\title{
Results of radial head resection after Mason type 3 or 4 fracture of the elbow
}

\author{
Ferdinand Nyankoue Mebouinz, Amadou Kasse, Mouhamadou Habib Sy \\ Department of Orthopedic Trauma Surgery, Idrissa Pouye General Hospital, Cheikh Anta Diop University, Dakar, Senegal
}

\begin{abstract}
Background: Resection of the radial head is a surgical indication for comminuted radial head fracture in which internal fixation is inaccessible. Some complications from the surgery can alter the function of the patient's elbow. The objective of this study was to assess functional outcome of the elbow after resection of the radial head.

Methods: A retrospective longitudinal study was performed with patients who underwent radial head resection between 2008 and 2018. Elbow function was assessed by the Mayo Elbow Performance Index (MEPI) for 11 patients comprising three women and eight men. The mean follow-up was 47.6 months. The mean age was $41 \pm 10.3$ years.

Results: Nine patients had a stable and painless elbow. The mean extension-flexion arc was $97.73^{\circ} \pm 16.03^{\circ}$. The mean values of pronation and supination were $76.8^{\circ}$ and $74.5^{\circ}$, respectively. The mean MEPI score was 83.2 points, and restoration of overall function was achieved in $81 \%$ of the cases. Poor function was noted in one in 10 that presented with a terrible triad.

Conclusions: Resection of the radial head restored elbow functionality at a rate of $81 \%$, which was a good outcome for patients.
\end{abstract}

Keywords: Radial head; Resection; Elbow; Function

\section{INTRODUCTION}

The functional anatomy of the elbow joint complex is unique in orientation and configuration. The elbow is the mechanical junction between the first two segments of the upper limb, and its main function is to move the hand away from and bring it closer to the trunk [1]. To perform these actions, this joint must be mobile, stable, and mostly painless. The head of the radius is a secondary stabilizer of the elbow according to Morrey's tripod [2]. It contributes to the overall stability of the elbow and the transmission of stresses, whatever the degree of extension flexion [3]. Its role in frontal and rotational stability has been highlighted by several authors $[2,4,5]$. Fractures of the head of the radius represent $1.5 \%$ to $4 \%$ of all fractures and $33 \%$ of all bone lesions in the elbow [6]. In these fractures, internal fixation of types 3 and 4 of the Masson classification, modified by Broberg and Morrey [7], is difficult and may not be possible in some cases $[7,8]$. The choice between resection of the radial head or arthroplasty is dependent on the associated ligament lesions, the equipment available, and the technical skills of the surgical teams. This study aimed to assess the function of the elbow after resection of the radial head in adults.

\section{Financial support: None.}

Conflict of interest: None.

Copyright@ 2020 Korean Shoulder and Elbow Society. All Rights Reserved.

This is an Open Access article distributed under the terms of the Creative Commons Attribution Non-Commercial License (http://creativecommons.org/licenses/by-nc/4.0/) which permits unrestricted non-commercial use, distribution, and reproduction in any medium, provided the original work is properly cited. 


\section{METHODS}

The ethics committee of Idrissa Pouye General Hospital approved this study (IRB No. 2018-06-014), which was exempted from informed consent.

\section{Patients}

A retrospective longitudinal study was carried out in the Department of Orthopedic Trauma Surgery, Idrissa Pouye General Hospital. The study enrolled patients who underwent radial head resection between 2008 and 2018. Using the electronic register of hospitalizations, files obtained from the archives were analyzed. Eleven of 28 patients who underwent radial head resection during this period were reviewed and included in this study. These were eight men and three women with an average age of $41 \pm 10.3$ years. The fractures were located on the dominant arm in half of the cases. The cause of injury was usually a work accident (54.5\%). Type III of the Mason classification modified by Morrey was found in 54.5\%. Posterior elbow dislocation and a fracture of the coronoid process were associated in five and three cases, respectively. There were three cases of terrible triads. The lateral surgical approach was used to access the radial head in 10 cases. The interval from initial injury to operation was $15.4 \pm 13$ days. The level of radial resection was distal to the proximal radial notch of the ulna in $63.6 \%$ of cases. The radial stump was regular and without bone indentation in $72.7 \%$ of the cases. Interposition of fascia was performed in all patients to address the empty space left after radial head resection. The fascia was taken from the extensor digitorum communis. Complementary procedures were reduction of dislocation and synthesis of associated fractures of the coronoid process. On average, the mean elbow immobilization time was $30.4 \pm 6$ days. Elbow function was assessed in all patients using the Mayo Elbow Performance Index (MEPI), and the values were scored by a single physician.

\section{Statistical Analysis}

Data were captured and analyzed using Epi Info ver. 7.1.5.2 (Centers for Disease Control and Prevention, Atlanta, GA, USA). General patient characteristics and MEPI score items were described using standard descriptive statistics. Mean values and standard deviations were calculated for quantitative variables and numbers and percentages for qualitative variables.

\section{RESULTS}

At an average follow-up of 47.6 months, of the 11 patients reassessed, two had mild mechanical pain. Six patients had a func- tional arc greater than $100^{\circ}$, and this arc varied from $50^{\circ}$ to $100^{\circ}$ in the other 5 . In regard to elbow mobility (Table 1 ), the average degree of flexion was $97.73^{\circ} \pm 16.03^{\circ}$ and the average deficit of extension was $23.6^{\circ}$. The mean pronation and supination values were $76.8^{\circ}$ and $74.5^{\circ}$, respectively. Overall, a cubitus valgus with an average value of $12.8^{\circ} \pm 4^{\circ}$ was identified. Instability as assessed by forced valgus movements was present at a moderate degree in two of 11 cases and was absent in the other nine. A cumulative total of 21 complications was found in all patients. In eight cases, the issue was a limitation of the range of motion, seven cases had elbow valgization (Fig. 1), two cases had instability in the valgus (Figs. 2 and 3), and four cases had heterotopic ossifications (Figs. 4 and 5). No complications such as radial head ascension or Essex-Lopresti syndrome were noted. There were no daily activity limitations in 10 cases. Seven patients continued their professional activities, three had to adjust their original jobs, and one patient had not yet returned to work. The average score for all patients was $83.2 \pm 11$ points out of 100 , and $81 \%$ were graded as good according to the MEPI. Elbow function was excellent in three cases, good in six cases, and average in two cases (Fig. 6).

\section{DISCUSSION}

Resection of the radial head is a therapeutic indication of interest, and several authors have reported similar findings in the literature. Characteristics of average age, male predominance, and impairment of the dominant side were reported by Karlsson et al. [9] and Obert et al. [10]. Work accidents have been implicated in

Table 1. Range of motion of the elbow

\begin{tabular}{|c|c|c|c|c|}
\hline Setting & Mean $\left(^{\circ}\right)$ & Standard deviation $\left(^{\circ}\right)$ & $\operatorname{Min}\left(^{\circ}\right)$ & $\operatorname{Max}\left({ }^{\circ}\right)$ \\
\hline Flexion & 97.73 & 16.03 & 60 & 120 \\
\hline Extension deficit & -23.64 & 15.67 & 5 & 60 \\
\hline Pronation & 76.82 & 6.61 & 0 & 80 \\
\hline Supination & 74.55 & 10.3 & 0 & 85 \\
\hline Cubitus valgus & 12.8 & 4 & 10 & 20 \\
\hline
\end{tabular}

Fig. 1. Cumulative postoperative complications. 

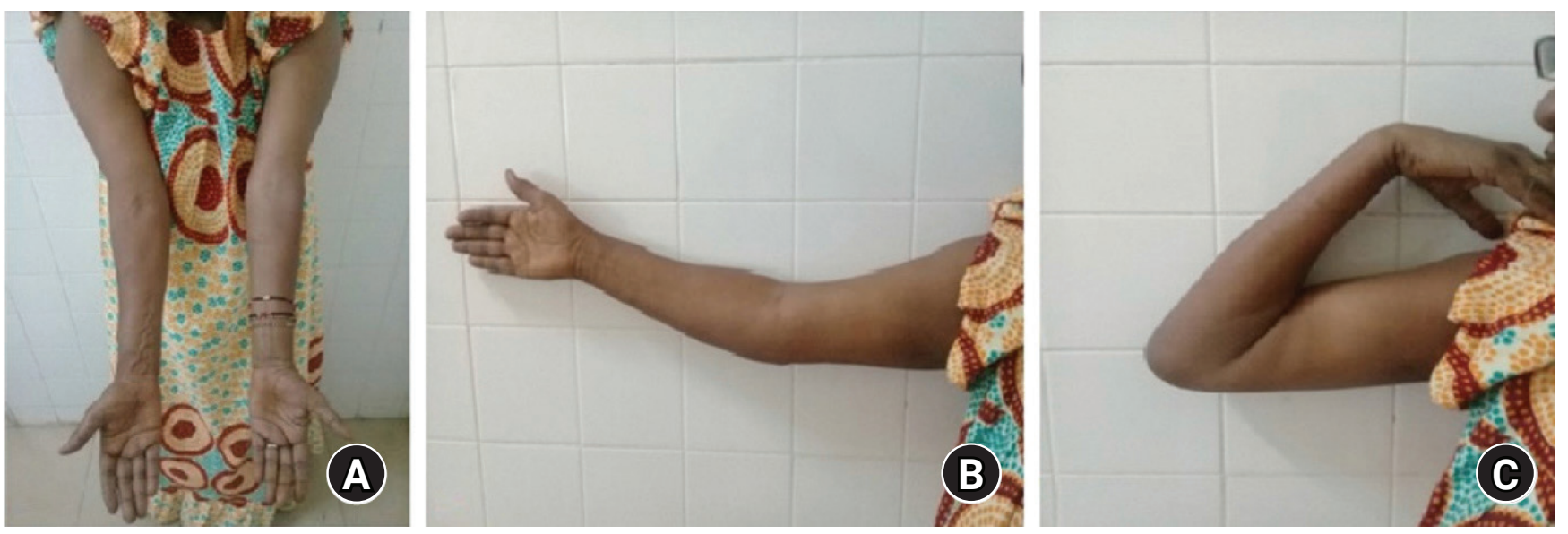

Fig. 2. The clinical result of case 1. (A) Cubitus valgus on the right. (B) Extension. (C) Full flexion.
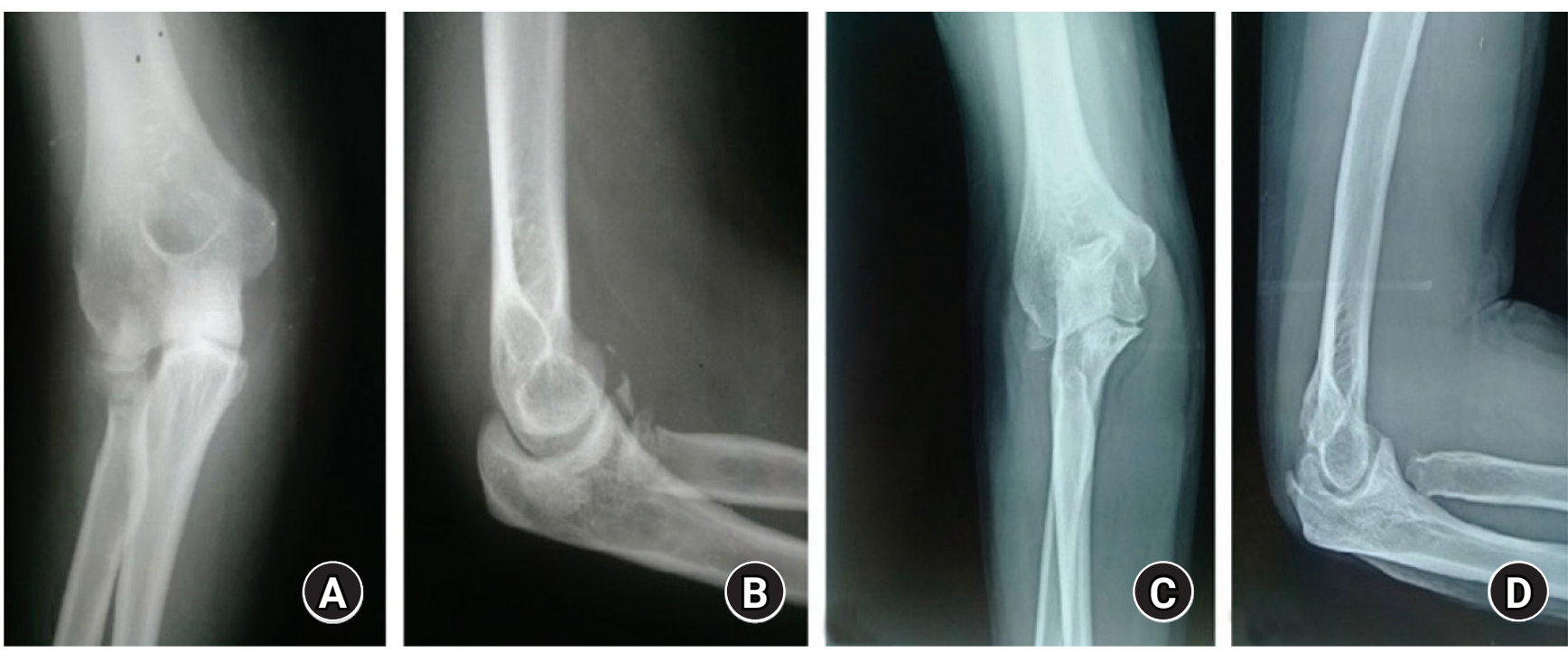

Fig. 3. The elbow radiography of case 1. (A, B) Face and post traumatic profile. (C, D) Face and profile at 61 months; no ossifications.
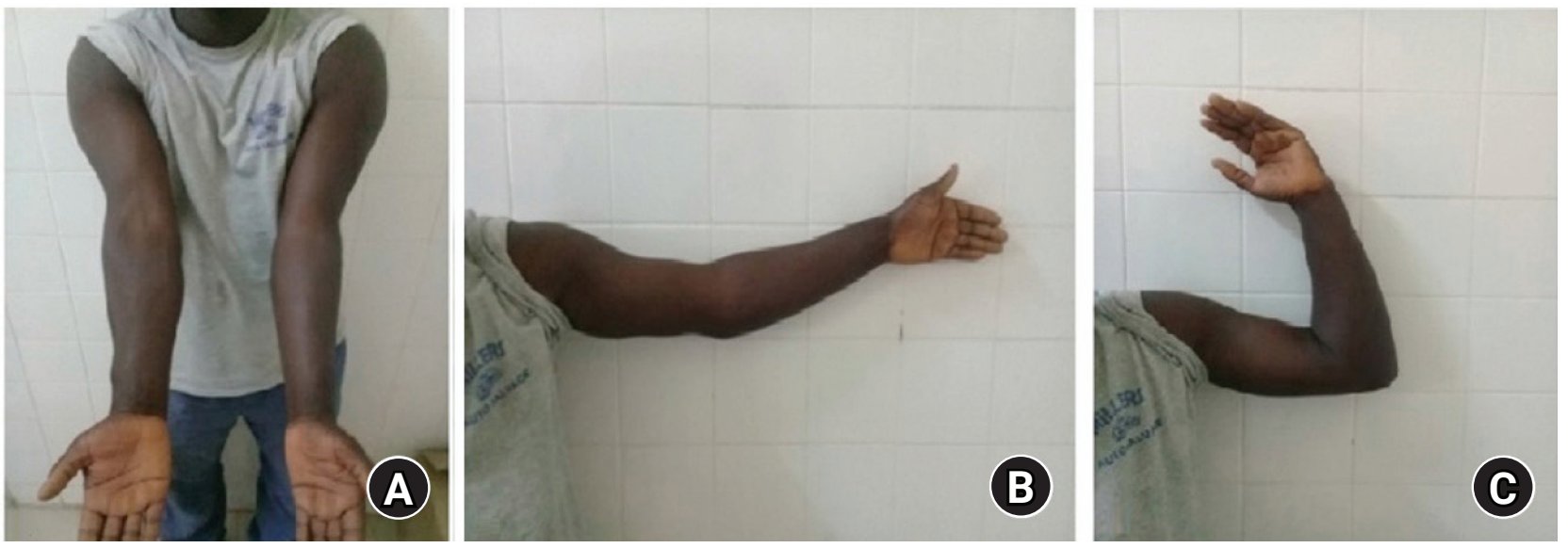

Fig. 4. The clinical result of case 2. (A) Cubitus valgus on the right. (B) Extension deficit of $25^{\circ}$. (C) Flexion limited to $100^{\circ}$. 

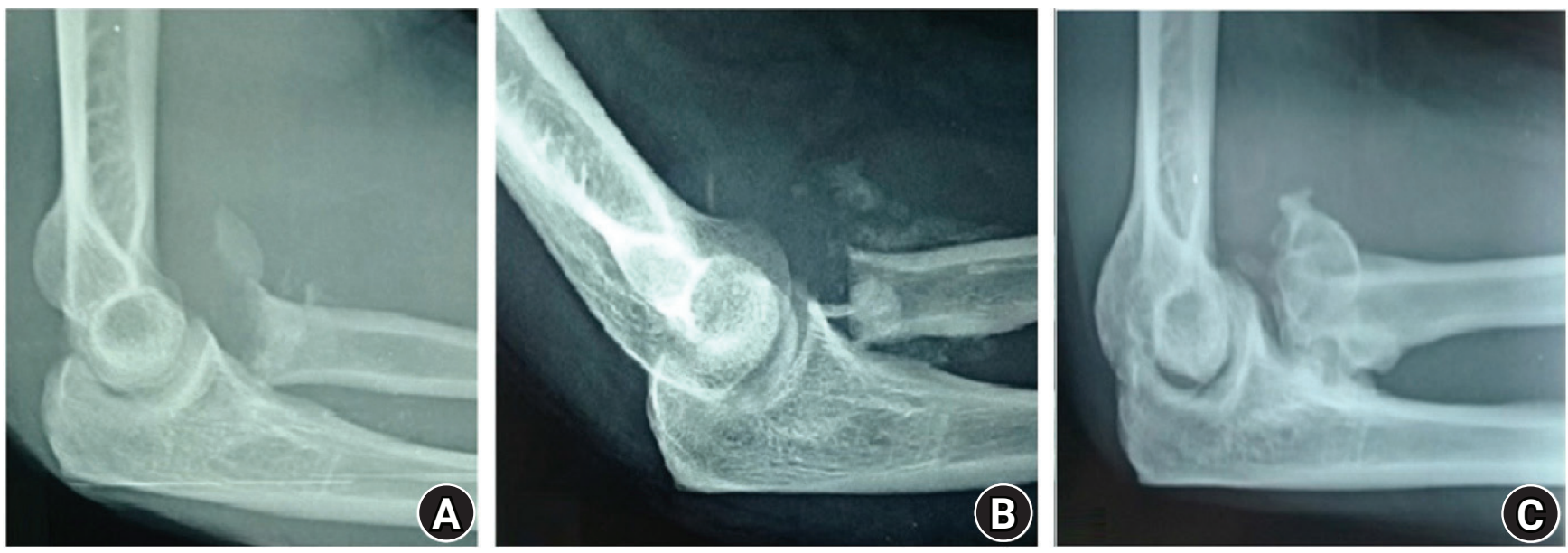

Fig. 5. The profile X-ray of case 2. (A) Posttraumatic. (B) Postoperative. (C) Heretopic ossifications at 19 months limiting flexion.

6

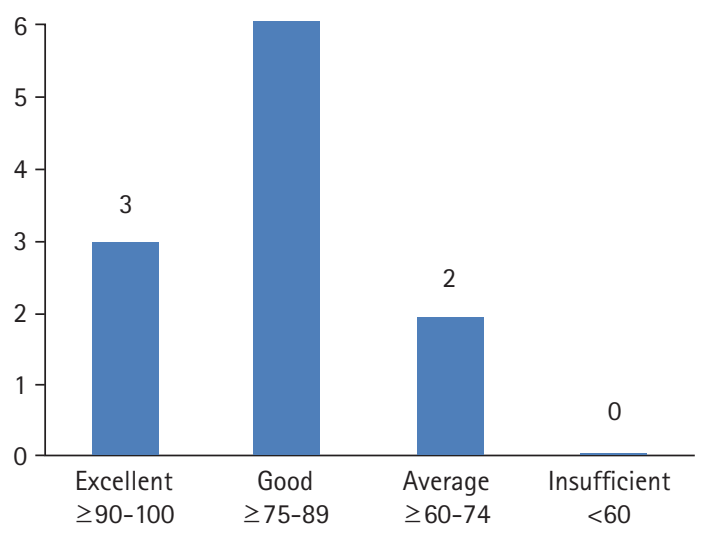

Fig. 6. Elbow function according to the Mayo Elbow Perfomance Index.

most studies as the main cause of injuries [10]. Type 3 and 4 fractures according to the Mason classification were the most common $[9,10]$. The time from initial injury to operation varied from 8 days on average in the study by Eren et al. [11] to 29 days in the report from Obert et al. [10]. Our average follow-up of 4 years was still quite short compared to other studies. The longest follow-up period observed was 19 years in the Karlsson et al. [9] study and 30 years in the Janssen and Vegter [12] study. Radial head resection surgery has associated complications that can interfere with elbow function. Ascension of the head and instability in the valgus are complications specific to this indication and are frequently accompanied by valgization of the elbow [12-14]. Other complications common to any joint surgery such as joint limitations and heterotopic ossifications are quite common [15]. These specific and non-specific complications are often responsible for stiffness that further affects the function of the elbow [16]. In this study, valgization of the elbow was found in $63.6 \%$ of the cases compared to $20 \%$ in the Karlsson et al. [9] study. However, there was slight valgus instability that was identified in only $18 \%$ $(2 / 11)$ of cases. This valgisation of the elbow had no impact on function. Antuña et al. [17] reported instability in the valgus at around 19\%, similar to our study. Similar to the reports from Karlsson et al. [9] and Antuña et al. [17], rise of the radial head was not reported in our series. Heterotopic ossifications were found in $36 \%$ of our cases compared to $62 \%$ in the study by Obert et al. [10] with an average follow-up of 16 years. These ossifications were usually found around the resection edge in cases that did not have the space filled after radial head resection. However, these results did not impair the range of motion of the elbow. Joint limitation occurred in five (45.4\%) of 11 patients. The range of joint limitation in these patients was between $50^{\circ}$ and $100^{\circ}$. The proportion of this complication is three times higher than that reported by Eren et al. [11]. This can be explained by the relatively long term of immobilization in our series, which was an average of $30 \pm 6$ days. Long-term immobilization has been identified as a source of stiffness [18,19]. Active mobilization immediately after removal of the radial head is currently recommended because it induces formation of a functional cervico-condylar neoarticulation [20]. Regarding elbow mobility, almost all sectors had results similar to those found in the literature, with the exception of flexion. The average value for flexion was quite low, and the difference ranged from $30^{\circ}$ to $40^{\circ}$, compared to results from Eren et al. [11], Karlsson et al. [9] and Antuña et al. [17]. This can be explained by the late start of mobilization or the osteoligamentary lesions in our series, dislocations in $45.4 \%$ of the cases (five cases of 11) and a terrible triad in three cases. In addition, the other studies had a longer rehabilitation period than ours, which may improve final results. Therefore, the functional score of the MEPI in our study was quite low, on aver- 
age 10 points lower than those of similar studies. However, this score of 83.2 points out of 100 ranked the patients in our series at an overall function level of $81 \%$. This level of function is judged to be good according to this assessment tool whose precision and reliability are internationally recognized [21]. The majority of patients was able to resume their professional activities without difficulty. This study had some limitations. First, due to the limited amount of follow-up and relatively small number of patients, the results cannot be generalized to a larger population. On the other hand, a relatively short-term follow-up in the revaluation did not allow us an overview of the long-term functionality. Finally, that the patients were operated on by several surgeons, and that some had additional osteoligamentary lesions, may have produced selection bias.

Despite the fairly limited size of this series, resection of the radial head for a fracture that cannot be operated on by internal fixation was associated with rather satisfactory results, with moderate loss of mobility. Notwithstanding mild clinical signs of instability, residual elbow pain and disability were mild. These results suggest that radial head resection remains a useful surgical procedure for irreparable radial head fractures.

\section{ACKNOWLEDGMENTS}

The authors thank all surgeons, physicians, and participants of this study.

\section{ORCID}

Ferdinand Nyankoue Mebouinz https://orcid.org/0000-0002-7302-0198 Amadou Kasse https://orcid.org/0000-0003-0175-1888 Mouhamadou Habib Sy https://orcid.org/0000-0003-3129-2379

\section{REFERENCES}

1. Kapandji IA. Physiologie articulaire du membre supérieur. E Livingstone 1980;1:70-4.

2. Morrey BF. Complex instability of the elbow. Instr Course Lect 1998;47:157-64.

3. Morrey BF, An KN, Stormont TJ. Force transmission through the radial head. J Bone Joint Surg Am 1988;70:250-6.

4. Morrey BF, Askew LJ, Chao EY. A biomechanical study of normal functional elbow motion. J Bone Joint Surg Am 1981; 63:872-7.

5. Morrey BF, An KN. Articular and ligamentous contributions to the stability of the elbow joint. Am J Sports Med 1983;11:315-9.

6. Duckworth AD, Clement ND, Jenkins PJ, Aitken SA, Court-
Brown CM, McQueen MM. The epidemiology of radial head and neck fractures. J Hand Surg Am 2012;37:112-9.

7. Broberg MA, Morrey BF. Results of delayed excision of the radial head after fracture. J Bone Joint Surg Am 1986;68:669-74.

8. Massin P, Hubert L, Toulemonde JL. Fractures of the upper end of the radius. EMC Surg Tech Orthopedics Traumatol 2002; 44326:9.

9. Karlsson MK, Herbertsson P, Nordqvist A, Besjakov J, Josefsson PO, Hasserius R. Comminuted fractures of the radial head. Acta Orthop 2010;81:224-7.

10. Obert L, Lepage D, Huot D, et al. Unreconstructible radial head fracture: resection, implant of Swanson or prosthesis? Retrospective comparative study. Chir Main 2005;24:17-23.

11. Eren OT, Tezer M, Armağan R, Küçükkaya M, Kuzgun U. Results of excision of the radial head in comminuted fractures. Acta Orthop Traumatol Turc 2002;36:12-6.

12. Janssen RP, Vegter J. Resection of the radial head after Mason type-III fractures of the elbow: follow-up at 16 to 30 years. J Bone Joint Surg Br 1998;80:231-3.

13. Pribyl CR, Kester MA, Cook SD, Edmunds JO, Brunet ME. The effect of the radial head and prosthetic radial head replacement on resisting valgus stress at the elbow. Orthopedics 1986;9:7236.

14. Taylor TK, O'connor BT. The effect upon the inferior radio-ulnar joint of excision of the head of the radius in adults. J Bone Joint Surg Br 1964;46:83-8.

15. Ritter MA, Gioe TJ. The effect of indomethacin on para-articular ectopic ossification following total hip arthroplasty. Clin Orthop Relat Res 1982;(167):113-7.

16. Chantelot C, Fontaine C, Migaud H, Remy F, Chapnikoff D, Duquennoy A. Retrospective study of 23 arthrolyses of the elbow for post-traumatic stiffness: result predicting factors. Rev Chir Orthop Reparatrice Appar Mot 1999;85:823-7.

17. Antuña SA, Sánchez-Márquez JM, Barco R. Long-term results of radial head resection following isolated radial head fractures in patients younger than forty years old. J Bone Joint Surg Am 2010;92:558-66.

18. King GJ, Evans DC, Kellam JF. Open reduction and internal fixation of radial head fractures. J Orthop Trauma 1991;5:21-8.

19. Esser RD, Davis S, Taavao T. Fractures of the radial head treated by internal fixation: late results in 26 cases. J Orthop Trauma 1995;9:318-23.

20. Bonnevialle P. Recent fractures of the proximal end of the forearm bones in the adult. EMC Appar Locomot 2001;34:1-14.

21. Cusick MC, Bonnaig NS, Azar FM, Mauck BM, Smith RA, Throckmorton TW. Accuracy and reliability of the Mayo Elbow Performance Score. J Hand Surg Am 2014;39:1146-50. 